\title{
VECTOR CONTROL OF A SINGLE-PHASE INDUCTION MACHINE WITH SCOTT-T CONNECTION IN THE STATOR AND ESTIMATION OF VELOCITY WITH SLIDING MODE OBSERVER
}

\author{
Paulo Cesar da Silva ${ }^{1}$, Horácio Beckert Polli ${ }^{2}$, Daniel dos Santos Matos ${ }^{3}$ \\ José de Oliveira $^{4}$, Ademir Nied ${ }^{5}$ \\ $1,4,5$ Santa Catarina State University, Joinville - Santa Catarina, Brazil \\ ${ }^{2}$ General Motors \\ ${ }^{3}$ Federal Institute of Paraná, Telemaco Borba and Santa Catarina State University, Joinville - Santa Catarina, Brazil \\ e-mail: paullo.cs@gmail.com, horaciobp@gmail.com,matos.s.daniell@gmail.com \\ jose.oliveira@udesc.br, ademir.nied@udesc.br
}

\begin{abstract}
This paper shows a high-performance sensorless driver for an induction machine with a Scott-T connection in the stator windings. This connection is used to transform a single-phase machine into a three-phase only by changing the winding configuration, increasing efficiency and minimizing the cost impact. This type of solution can be used as an alternative to the use of highperformance drivers controlling single-phase induction machines. The motor model using the Scott- $T$ connection is developed and the experimental results of a vector control approach by field orientation are shown. A sliding mode observer is also developed for estimating the speed of the machine tested.
\end{abstract}

Keywords - Field orientation control (FOC), Induction motor, Scott-T connection, Sensorless, Sliding mode observer (SMO).

\section{NOMENCLATURE}

$\begin{array}{ll}b & \text { Friction coefficient. } \\ i_{s q}, i_{s d} & \text { q-axis and d-axis stator currents. } \\ J & \text { Moment of the inertia. } \\ L_{r} & \text { Rotor self-inductance. } \\ M_{s r} & \text { Stator to rotor mutual inductance. } \\ P & \text { Number of pole pairs. } \\ R_{r} & \text { Rotor resistance. } \\ R_{s} & \text { Stator resistance. } \\ T_{L} & \text { Torque of the load. } \\ v_{s q}, v_{s d} & \text { q-axis and d-axis stator voltages. } \\ \varphi_{r d}, \varphi_{r q} & \text { q-axis and d-axis rotor fluxes. } \\ \varphi_{s d}, \varphi_{s q} & \text { q-axis and d-axis stator fluxes. } \\ \tau_{r} & \text { Rotor time constant. } \\ \omega_{e} & \text { Electrical speed. } \\ \omega_{r} & \text { Rotor speed. } \\ \omega_{s l} & \text { Slip speed. }\end{array}$

\section{INTRODUCTION}

At the end of the 1890's, Charles F. Scott, engineer for the Westinghouse Electric and Manufacturing Company developed a transformer with the capacity of transforming two-phase into three-phase systems. The connection became

Manuscript received 01/08/2018; first revision 25/09/2018; accepted for publication 27/03/2019, by recommendation of Editor Marcello Mezaroba. http://dx.doi.org/10.18618/REP.2019.2.0028 known as the Scott-T connection, because of the name of the inventor and the " $T$ " shape of the connection on the threephase side [1].

The Scott-T connection can be used in the stator of a singlephase motor as well. The advantage of using this connection is that a single-phase motor can be transformed in a threephase motor, just by changing the windings configuration. There is no need for extra tools to make new stator and rotor laminations in a production line if this connection is used [1].

Single-phase induction motors (SPIMs) are widely used, especially for residential applications. These motors are usually at fractional horsepower level and thus are suitable for deployment in residential appliances such as air-conditioners, washing machines, dryers, and refrigerators [2]-[7]. However, generally, the use of these motors presents low efficiency in transients and no controllers are used for the improvement of the dynamics.

The energy saving is one of the important topics nowadays to reduce the energy bill costs and preserve the environment. Therefore, products with high efficiency are indispensable for the fulfillment of the objective of reducing energy consumption and meeting the demand of consumers [8]. Reference [9] shows a significant gain of efficiency using a frequency inverter in the drive of a single-phase induction motor to a washing machine. However, the use of single-phase motors for this type of application is not optimized because the neutral current can be up to $41 \%$ higher than the phase currents, making the cost of the frequency inverter higher than necessary. Another problem associated with the solution proposed by [9] is the use of a speed sensor, which in addition to the cost associated with the component, is still subject to failure, compromising the operation of the system.

Generally, applications of this type still have low volume so that the high design costs of a new motor and a new mechanical interface of the platform (in this case an appliance) with the motor can make the project unfeasible. The use of a motor with the Scott-T connection in the stator can help to solve two of the problems involved: the high neutral current and the costs of tooling to manufacture a low volume motor. The motor with the Scott-T connection in the stator, because it is a two-phase motor connected as a three-phase still has an imbalance in the phase electric currents. This imbalance is in the order of $15 \%$, which is much smaller than the $41 \%$ of the single-phase induction motor. This motor can still be produced on the same production line as a single-phase motor, using the same stator and rotor laminations, requiring no investment 


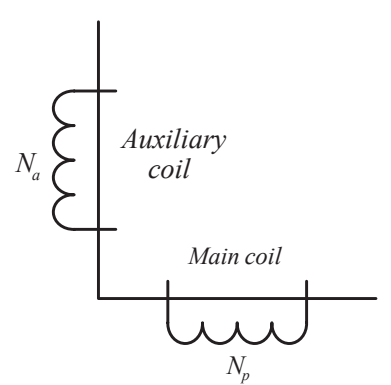

Fig. 1. Single-phase motor stator connection.
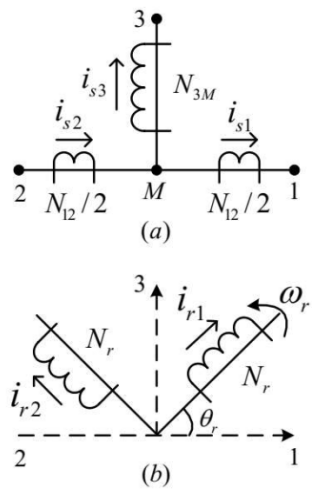

Fig. 2. Stator Connection (a) and rotor connection (b) of the Scott-T Motor.

in tooling and a new production line. In addition, from the outside the motor is exactly the same as the single-phase motor from which it was derived, requiring no modifications to the mechanical interface with the platform on which the motor is being used.

An electronic driver is commonly used nowadays for speed control in electrical machines, especially in appliances. The most common topology for these drivers is the three-phase inverters used with a three-phase machine [10].

The use of single-phase machines with an inverter is proposed in [11] and [12], but the overall cost of these inverters is increased because of the neutral current of the motor. The motor with a Scott-T connection can be used with a threephase inverter, keeping the advantages of three-phase motors and it still keeps the retrofit feature of a single-phase machine, because it has the same mechanical structure.

\section{INDUCTION MOTOR WITH SCOTT-T CONNECTION IN STATOR}

It is possible to make the T-connection on any singlephase motor with two coils and a starting capacitor, thus transforming it into a three-phase motor. Taking advantage of the same mechanical structure of a single-phase motor with the auxiliary coil and the main coil exactly alike, it is possible to wind the stator coils differently to fit the T-connection in the stator. Figure 1 shows the connection of a single-phase motor from which the Scott-T motor was derived, where the subscript $p$ indicates quantities related to the main winding, and the subscript $a$ indicates quantities related to the auxiliary winding.

Since the original motor has equal phases, the following relations applies for the number of turns, inductance and

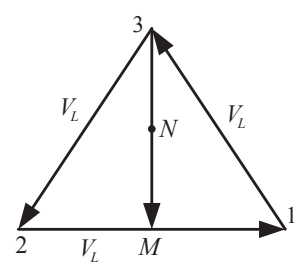

Fig. 3. Voltage modules applied to the motor.

resistance of main and auxiliary windings:

$$
N_{p}=N_{a} \quad ; \quad L_{p}=L_{a} \quad ; \quad R_{p}=R_{a}
$$

The connection between the main coil and the auxiliary coil is transferred to the middle of one of the coils and the winding which is connected to that center is wound with a different number of turns, making the flux amplitude balanced between both axes. The new phases are then connected to a three-phase inverter in Figure 2.a.

Considering that the motor is running in a sinusoidal steady-state, the Figure 3 shows the phasors of the motor supply voltage, where $V_{L}$ is the line voltage.

By trigonometric analysis, the voltage modulus $V_{3 M}$ is given by:

$$
V_{3 M}=\sqrt{V_{L}^{2}-\frac{V_{L}^{2}}{2^{2}}} \quad \therefore \quad V_{3 M}=\frac{\sqrt{3} V_{L}}{2} .
$$

In order for the fluxes generated in the two circuits (auxiliary and main) to have equal amplitudes, it is necessary that the ratio of turns between the circuits is equal to the voltage ratio, therefore:

$$
\frac{N_{3 M}}{N_{12}}=\frac{\frac{\sqrt{3} V_{L}}{2}}{V_{L}} \quad \therefore \quad N_{3 M}=\frac{\sqrt{3} N_{12}}{2} .
$$

This new winding will be done on top of the main winding of the motor, also having the same mechanical dimensions and spatial distribution of the previous winding. By keeping the same copper weight, the change in the number of turns causes the inductance and resistance parameters of the new circuit to be related to the old circuit by the square of the turns ratio [13], therefore:

$$
\begin{gathered}
\frac{N_{3 M}}{N_{12}}=\frac{\sqrt{3}}{2}=a . \\
L_{3 M}=a^{2} L_{p} \quad ; \quad R_{3 M}=a^{2} R_{p} .
\end{gathered}
$$

Considering that the motor had two balanced phases before being rewound, one can relate the parameters of the new phase to the parameters of the old phase.

\section{SCOTT-T INDUCTION MOTOR MODEL}

The Figure 2 shows the Scott-T motor stator and rotor connection. The same mechanical structure of a single-phase induction machine that has the main winding equal to the auxiliary winding, can be used to assemble a three-phase induction machine, using the Scott-T connection. Basically, one of the windings is rewound with less number of turns and connected to the middle point of the other winding. The number of winding turns will be determined by keeping the 
rotor flux amplitude in both axes equal. With this in mind, the rotor of the motor can be modeled by two symmetrical windings with $90^{\circ}$ from each other [1].

The complete modeling of the machine can be found in [1]. Next, the state space is presented, using as states the rotor fluxes, the stator currents, and rotor speed,

$$
\begin{aligned}
{\left[\begin{array}{c}
\dot{i}_{s \alpha} \\
\dot{i}_{s \beta} \\
\dot{\varphi}_{r \alpha} \\
\dot{\varphi}_{r \beta} \\
\dot{\omega}_{r}
\end{array}\right]=} & {\left[\begin{array}{ccccc}
\gamma & 0 & \frac{M_{s r}}{L_{\sigma} L_{r} \tau_{r}} & \frac{M_{s r} \omega_{r}}{L_{\sigma} L_{r}} & 0 \\
0 & \gamma & -\frac{M_{s r} \omega_{r}}{L_{\sigma} L_{r}} & \frac{M_{s r}}{L_{\sigma} L_{r} \tau_{r}} & 0 \\
\frac{M_{s r}}{\tau_{r}} & 0 & -\frac{1}{\tau_{r}} & \omega_{r} & 0 \\
0 & \frac{M_{s r}}{\tau_{r}} & -\omega_{r} & \frac{1}{\tau_{r}} & 0 \\
0 & 0 & \frac{P M_{s r} i_{s \beta}}{J L_{r}} & \frac{P M_{s r} r_{s \alpha}}{J L_{r}} & \frac{b}{J}
\end{array}\right]\left[\begin{array}{c}
i_{s \alpha} \\
i_{s \beta} \\
\varphi_{r \alpha} \\
\varphi_{r \beta} \\
\omega_{r}
\end{array}\right] } \\
+ & {\left[\begin{array}{ccc}
\frac{1}{L_{\sigma}} & 0 & 0 \\
0 & \frac{1}{L_{\sigma}} & 0 \\
0 & 0 & 0 \\
0 & 0 & 0 \\
0 & 0 & \frac{1}{J}
\end{array}\right]\left[\begin{array}{c}
v_{s \alpha} \\
v_{s \beta} \\
T_{L}
\end{array}\right] . }
\end{aligned}
$$

The constants $J$ and $b$ are the moment of the inertia and the friction coefficient of the system, respectively; $T_{L}$ is the resistive torque of the load; $L_{r}$ and $M_{s r}$ are respectively, the rotor self-inductance and the stator to rotor mutual inductance on the stator stationary frame.

The constants in the model are given by:

$$
\begin{gathered}
L_{\sigma}=L_{s}\left(1-\frac{M_{s r}^{2}}{L_{s} L_{r}}\right) ; \gamma=-\frac{1}{L_{\sigma}}\left(R_{s}+\frac{M_{s r}^{2}}{L_{r} \tau_{r}}\right) \\
\tau_{r}=\frac{L_{r}}{R_{r}} .
\end{gathered}
$$

\section{VECTOR CONTROL}

Vector control by magnetic flux orientation transforms the dynamics of the AC motor similar to that of a separate excitation DC machine. That is, this control promotes a decoupling between AC motor flux and torque, and these quantities are controlled separately, as with DC machines [10], [14].

For the implementation of this control technique, it is common to express the motor model in a rotating reference frame. If this rotating frame is in synchronism with the magnetic field angular speed, the new for the machine can be given by:

$$
\begin{gathered}
v_{s d}=R_{s} i_{s d}+\frac{d \varphi_{s d}}{d t}-\omega_{e} \varphi_{s q} \\
v_{s q}=R_{s} i_{s q}+\frac{d \varphi_{s q}}{d t}+\omega_{e} \varphi_{s d} \\
0=R_{r} i_{r d}+\frac{d \varphi_{r d}}{d t}-\left(\omega_{e}-\omega_{r}\right) \varphi_{r q} \\
0=R_{r} i_{r q}+\frac{d \varphi_{r q}}{d t}+\left(\omega_{e}-\omega_{r}\right) \varphi_{r d} \\
\varphi_{s d}=L_{s} i_{s d}+M_{s r} i_{r d} \\
\varphi_{s q}=L_{s} i_{s q}+M_{s r} i_{r q} \\
\varphi_{r d}=L_{r} i_{r d}+M_{s r} i_{s d} \\
\varphi_{r q}=L_{r} i_{r q}+M_{s r} i_{s q}
\end{gathered}
$$

where $\left(\omega_{e}-\omega_{r}\right)$ is the slip speed. The electrical-magnetic torque will be given by:

$$
T_{e}=\frac{P M_{s r}}{L_{r}}\left(i_{s q} \varphi_{r d}-i_{s d} \varphi_{r q}\right) .
$$

$P$ is the number of pole pairs.

By isolating the rotor currents on (15) and (16), and substituting on (11) and (12), yields:

$$
\begin{aligned}
& \tau_{r} \frac{d \varphi_{r d}}{d t}+\varphi_{r d}=M_{s r} i_{s d}+\tau_{r} \omega_{s l} \varphi_{r q} \\
& \tau_{r} \frac{d \varphi_{r q}}{d t}+\varphi_{r q}=M_{s r} i_{s q}-\tau_{r} \omega_{s l} \varphi_{r d}
\end{aligned}
$$

where $\tau_{r}$ is the rotor time constant, and $\omega_{s l}$ is the slip speed. By choosing the slip speed as:

$$
\omega_{s l}=\frac{M_{s r} i_{s q}}{\tau_{r} \varphi_{r d}}
$$

and substituting (20) in (19):

$$
\tau_{r} \frac{d \varphi_{r q}}{d t}+\varphi_{r q}=0
$$

By proper choice of the slip speed, it is possible to align the rotor flux vector with the $d$-axis of the rotating frame. So, if $\varphi_{r q}=0$ is achieved, the $d$-axis rotor flux may be expressed as:

$$
\tau_{r} \frac{d \varphi_{r d}}{d t}+\varphi_{r d}=M_{s r} i_{s d}
$$

When the rotor flux is set as:

$$
\varphi_{r d}=M_{s r} i_{s d}
$$

the torque equation can be rewritten as:

$$
T_{e}=\frac{P M_{s r} \varphi_{r d} i_{s q}}{L_{r}}
$$

The $q$-axis stator current can be used to control the machine torque, while the $d$-axis current is kept constant to set the machine rated flux.

\section{SLIDE MODE OBSERVER}

The accuracy of the open loop estimation models reduces as the mechanical speed reduces. The limit of acceptable performance depends on how precisely the model parameters can be matched to the corresponding parameters in the actual machine. It is particularly at lower speeds that parameter deviations have a significant influence on the steady-state and dynamic performance of the drive system. The robustness against parameter mismatch and signal noise can be improved by employing closed loop observers for the estimation of the state variables, and possibly of the system parameters [1].

Sliding mode observers (SMO) can be used to this purpose, because of their inherent features such as robustness, system order reduction, disturbance rejections, parameters insensitivity [15], [16].

Closing the feedback using one unknown part of the model 
as slide mode function make the observer. Slide mode function always represents gained error between the observed and actual value of stator currents. The stability condition is achieved by having a very large gain in the slide function [1].

By taking part of the motor rotor flux state spaces in the stationary frame (6), and using the following slide mode function yields:

$$
\begin{gathered}
{\left[\begin{array}{c}
\varphi_{\alpha S F} \\
\varphi_{\beta S F}
\end{array}\right]=\left[\begin{array}{c}
\frac{\hat{\varphi}_{r \alpha}}{\tau_{r}}+\omega_{r} \hat{\varphi}_{r \beta} \\
\frac{\hat{\varphi}_{r \beta}}{\tau_{r}}-\omega_{r} \hat{\varphi}_{r \alpha}
\end{array}\right] .} \\
{\left[\begin{array}{c}
\varphi_{\alpha S F} \\
\varphi_{\beta S F}
\end{array}\right]=-G\left[\begin{array}{c}
\operatorname{sign}\left(\hat{i}_{s \alpha}-i_{s \alpha}\right) \\
\operatorname{sign}\left(\hat{i}_{s \beta}-i_{s \beta}\right)
\end{array}\right] .}
\end{gathered}
$$

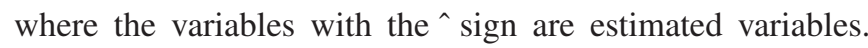
Substituting (26) in (6), the current and rotor flux state space equation is:

$$
\begin{gathered}
{\left[\begin{array}{c}
\frac{d \hat{i}_{s \alpha}}{d t} \\
\frac{d i_{s \beta}}{d t}
\end{array}\right]=\frac{1}{L_{\sigma}}\left[\begin{array}{c}
v_{s \alpha} \\
v_{s \beta}
\end{array}\right]-\frac{1}{L_{\sigma}}\left(R_{s}+\frac{M_{s r}^{2}}{L_{r} R_{r}}\right)\left[\begin{array}{l}
\hat{i}_{s \alpha} \\
\hat{i}_{s \beta}
\end{array}\right]} \\
+\frac{M_{s r}}{L_{\sigma} L_{r}}\left[\begin{array}{c}
\varphi_{\alpha S F} \\
\varphi_{\beta S F}
\end{array}\right] . \\
{\left[\begin{array}{c}
\frac{d \hat{\varphi}_{r \alpha}}{d t} \\
\frac{d \hat{\varphi}_{r \beta}}{d t}
\end{array}\right]=\frac{M_{s r}}{\tau_{r}}\left[\begin{array}{l}
\hat{i}_{s \alpha} \\
\hat{i}_{s \beta}
\end{array}\right]-\left[\begin{array}{c}
\varphi_{\alpha S F} \\
\varphi_{\beta S F}
\end{array}\right] .}
\end{gathered}
$$

With (27) and (28) it is possible to calculate the observed values of the stator current and rotor flux. On the real implementation for the calculation of the stator currents, a simple integrator discretized by a trapezoidal function is giving good results, because of the closed loop in the current path. For the rotor flux observer, a quasi-integrator was necessary because of drift problems.

A linear region was also added to the SMO sign function, in order to reduce the SMO chattering on the real world implementation.

From the slide function (25) it is possible to calculate the rotor speed by isolation the rotor time constant $\tau_{r}$, then the observed speed will be given by:

$$
\omega_{r}=\frac{\hat{\varphi}_{r \beta} \varphi_{\alpha S F}-\varphi_{\beta S F} \hat{\varphi}_{r \alpha}}{\hat{\varphi}_{r \alpha}^{2}+\hat{\varphi}_{r \beta}^{2}} .
$$

\section{A. Stability of the Sliding Mode Observer}

Since the signal function is a nonlinear function, it is necessary to use the Lyapunov stability theorem to analyze the stability of the slider observer. The Lyapunov candidate function for the sliding mode function can be considered as,

$$
V=\frac{I_{e}^{T} I_{e}}{2}
$$

where,

$$
I_{e}=\left[\begin{array}{c}
\hat{i}_{s \alpha}-i_{s \alpha} \\
\hat{i}_{s \beta}-i_{s \beta}
\end{array}\right]
$$

The matrix $I_{e}^{T}$ represents the transpose of the $I_{e}$ matrix. The derivative of the Lyapunov candidate function with respect to time is given by:

$$
\frac{d V}{d t}=I_{e}^{T} \frac{d I_{e}}{d t}
$$

The next step is to subtract (27) from the current shown in (6), thus obtaining:

$$
\frac{d I_{e}}{d t}=\gamma I_{e}+\frac{M_{s r}}{L_{\sigma} L_{r}} \varphi_{S F}-\frac{M_{s r}}{L_{\sigma} L_{r}} A \hat{\varphi}_{r}
$$

where,

$$
\begin{gathered}
\frac{d I_{e}}{d t}=\left[\begin{array}{c}
\frac{d \hat{i}_{s \alpha}}{d t}-\frac{d i_{s \alpha}}{d t} \\
\frac{d \hat{i}_{s \beta}}{d t}-\frac{d i_{s \beta}}{d t}
\end{array}\right] \\
\varphi_{S F}=\left[\begin{array}{c}
\varphi_{\alpha S F} \\
\varphi_{\beta S F}
\end{array}\right] ; \quad \hat{\varphi}_{r}=\left[\begin{array}{c}
\hat{\varphi}_{r \alpha} \\
\hat{\varphi}_{r \beta}
\end{array}\right] . \\
A=\left[\begin{array}{cc}
\frac{1}{\tau_{r}} & \omega_{r} \\
-\omega_{r} & \frac{1}{\tau_{r}}
\end{array}\right] .
\end{gathered}
$$

Lyapunov's stability condition says that:

$$
\frac{d V}{d t}=I_{e}^{T} \frac{d I_{e}}{d t}<0
$$

Substituting (33), (26) and the transpose of (31) into (37):

$$
\begin{aligned}
& -\frac{1}{L_{\sigma}}\left(R_{s}+\frac{M_{s r}^{2}}{L_{r} R_{r}}\right) I_{e}^{T} I_{e}-\frac{M_{s r}}{L_{\sigma} L_{r}} G I_{e}^{T} \operatorname{sign}\left(I_{e}\right) \\
& -\frac{M_{s r}}{L_{\sigma} L_{r}} I_{e}^{T} A \hat{\varphi}_{r}<0 .
\end{aligned}
$$

Resolving inequality (38):

$$
G>\frac{\left|I_{e}^{T} A \hat{\varphi}_{r}\right|-\frac{\frac{1}{L_{\sigma}}\left(R_{s}+\frac{M_{s r}^{2}}{L_{r} R_{r}}\right) I_{e}^{T} I_{e}}{M_{s r} / L_{\sigma} L_{r}}}{\left|\hat{i}_{s \alpha}-i_{s \alpha}\right|+\left|\hat{i}_{s \beta}-i_{s \beta}\right|} .
$$

The (39) shows the stability condition of the slider observer relative to its gain. Making large enough to fit (39) the sliding mode observer will be stable.

\section{CONTROL IMPLEMENTATION}

The control of the motor with the T connection is similar to the three-phase machine. Figure 4 shows the diagram block of the control using the SMO.

The motor used in the control was derived from a Permanent Split Capacitor (PSC) motor with two symmetrical windings (main and auxiliary windings). The stator of this motor was rewound with the Scott-T connection. Table I shows the parameters of the motor. The electrical parameters 
were taken by the no-load and blocked rotor tests and are already referred to the symmetrical two-phase model of the motor at $25^{\circ} \mathrm{C}$.

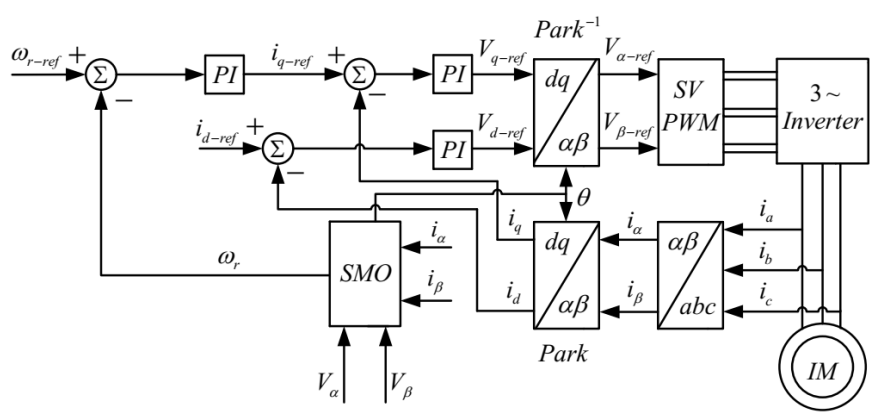

Fig. 4. Block diagram of the motor control.

The control was implemented on a development board with a digital signal controller (DSC) working with a sampling time of $62.5 \mu \mathrm{s}$. The control was designed in the $s$-plane and after this was discretized using the Tustin method.

All the s presented in this paper were discretized and implemented in a fixed-point logic. Additional second-orders effects compensations were made in order to maintain a robust control. These second-orders effects such as voltage drop across the IGBTs and diodes, stator resistance measurement before starting the motor, look-up table to compensate rotor saturation based on the slip and a modified space-vector strategy taking into account the motor topology presented in section II, were not presented into this paper due to space restrictions.

\section{TABLE I}

\section{Motor Parameters}

\begin{tabular}{cc}
\hline Parameter & Value \\
\hline Nominal voltage & $185 \mathrm{~V}$ \\
\hline Nominal current & $1.3 \mathrm{~A}$ \\
\hline Power & $\frac{1}{3} \mathrm{HP}$ \\
\hline Number of poles $(p)$ & 4 \\
\hline Stator resistance $\left(R_{s}\right)$ & $10.05 \Omega$ \\
\hline Rotor resistance $\left(R_{r}\right)$ & $13.83 \Omega$ \\
\hline Stator inductance $\left(L_{s}\right)$ & $247 m H$ \\
\hline Rotor inductance $\left(L_{r}\right)$ & $247 m H$ \\
\hline Mutual inductance $\left(M_{s r}\right)$ & $226 m H$ \\
\hline
\end{tabular}

\section{EXPERIMENTAL RESULTS}

The practical implementation of the induction motor with the Scott-T connection was made by the WEG company. For the design, a single-phase motor with the same primary and secondary windings was selected, generally used for washing machine applications. The motor was modified to have the Scott-T link in the stator and nominal voltage of $185 \mathrm{~V}$.

The results that are shown in this paper were achieved by using the motor connected to a Magtrol dynamometer model HD-800-6N. The data was acquired by using a Labview interface in a desktop computer. The interface uses serial communication with the control board and with the dynamometer controller, to have the data acquired at the same time. The connection between the motor axes and the dynamometer is made through a coupling. Figure 5 shows a picture of the experimental bench.

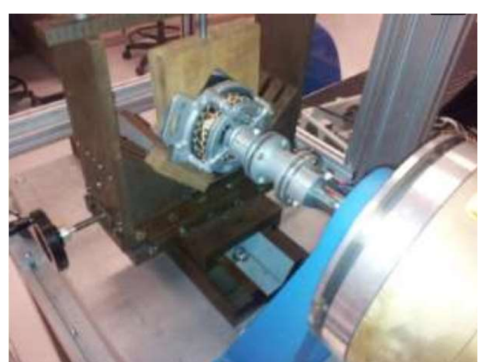

Fig. 5. Experimental Bench.

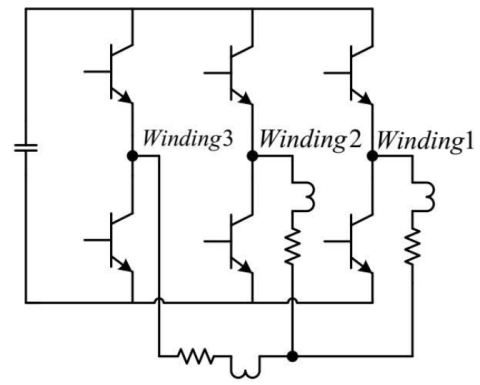

Fig. 6. Connecting the drive circuit with the motor.

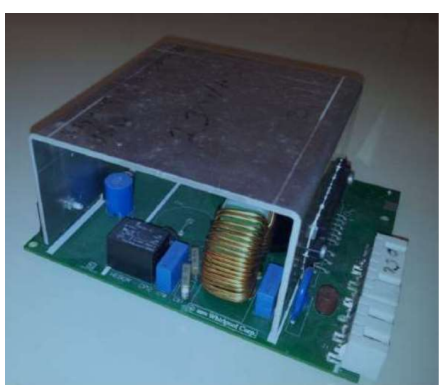

Fig. 7. Frequency inverter.

The rectifying circuit is composed of 4 diodes, for rectification of the AC signal, and by a capacitor to maintain the voltage in the DC bus. The sensor circuits are formed by shunts for acquiring current and operational amplifiers and passive elements for filtering the current signals. The drive circuit is composed of an integrated circuit containing 6 IGBT's, forming 3 arms. The connection of the drive circuit to the motor is shown in Figure 6.

The microprocessor used has the ARM architecture and uses a Cortex M-3 operating at $72 \mathrm{MHz}$. Figure 7 shows the picture of the frequency inverter used for this work. In the next subsections will show the tests results. Two different operating points will be analyzed to observe the effectiveness of the proposed control and speed estimation.

\section{A. Motor at 800 rpm with a Constant Load of $1 \mathrm{Nm}$}

Figure 8 shows the speed response of the control. With the load inserted into the system, the speed response does not present overshoot. Still in Figure 8 it is possible to notice the deterioration of the speed observed during the reversal of the motor because with the increase of the load in the system, the motor spends some seconds with zero speed. This time at zero speed is the time that the torque controller takes to respond to the torque step caused by the change of dynamic torque (moving motor) to static torque (motor stopped). The effect 
is not noticed during motor start-up, because during the start procedure the controller integrators are already pre-charged, which does not occur during the reversal.

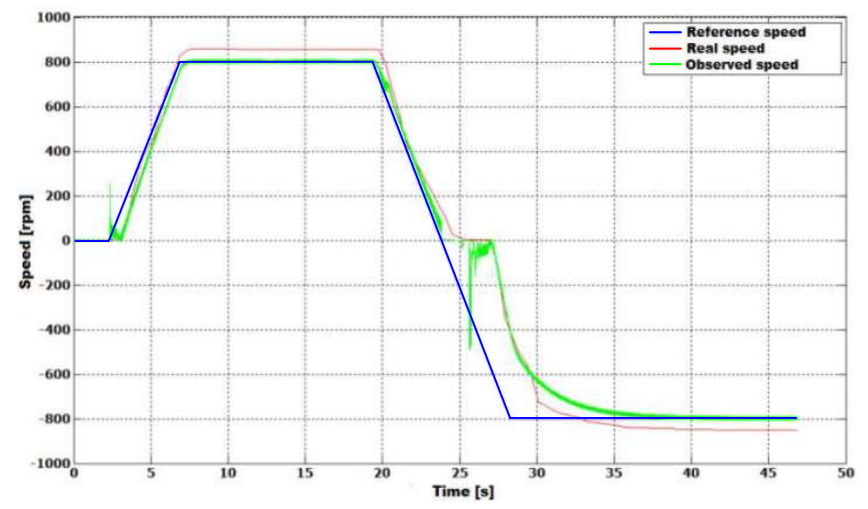

Fig. 8. Speed response at $800 \mathrm{rpm}$.

There is a steady-state error around $57 \mathrm{rpm}$ in relation to the actual speed, which represents a $7.13 \%$ error. The estimation error is mainly caused because of the rotor of this motor has closed slots. This characteristic causes the rotor to easily saturate, changing the rotor leakage inductance up to 10 times between locked rotor and the nominal operating point of the motor. To work with the motor using a sensorless algorithm in the high slip region, it is needed to compensate for this nonlinear effect.

Figure 9 shows the control of the currents of axis $d$ and $q$, where it is observed that the currents are superimposed on their references.

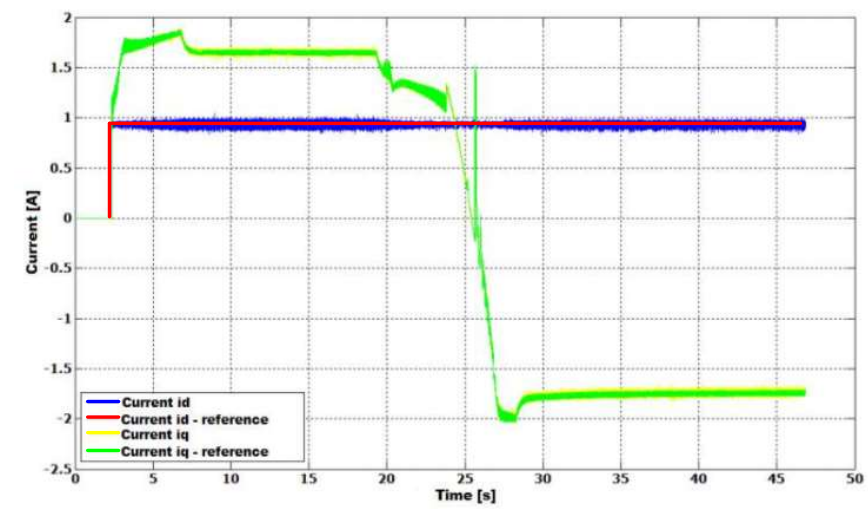

Fig. 9. Current control at 800 rpm.

Figures 10 and 11 show the currents of the $\alpha$ and $\beta$ axes, which are the currents of the steady reference frame. The steady-state $\alpha$-axis current has a peak value close to $1.8 \mathrm{~A}$, while for the $\beta$-axis this value is approximately $2.1 \mathrm{~A}$. This difference in values is observed because, in practice, the Scott$\mathrm{T}$ transformation makes the motor symmetrical, as long as the copper weight on both axes (ideal case) remains the same. That is, the parameters in the $\alpha$-axis are equal to those in the $\beta$-axis. In practice, because of the predetermined wire gauge sizes, the copper weight between the axes is not exactly the same, so that when the motor is referenced to a rotating shaft, the stator resistance terms are dependent on the position of the synchronous axis, falling in the same case as a single-phase induction motor with asymmetric windings [12].

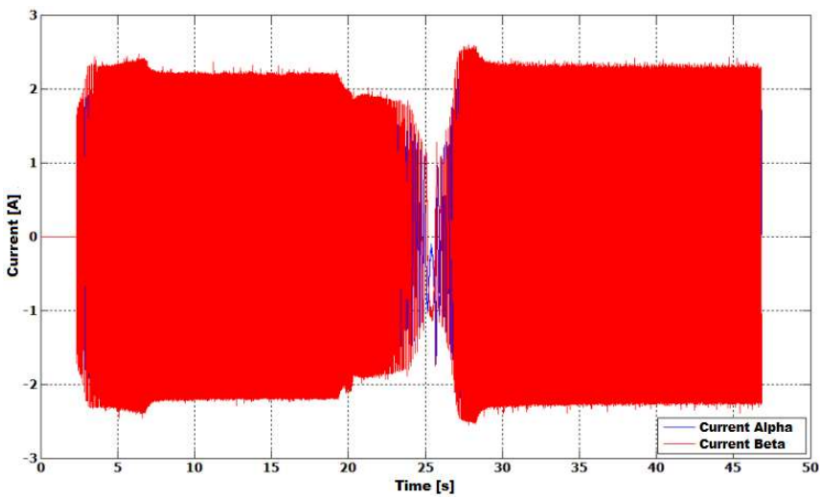

Fig. 10. $\alpha$ and $\beta$ axis currents at $800 \mathrm{rpm}$.

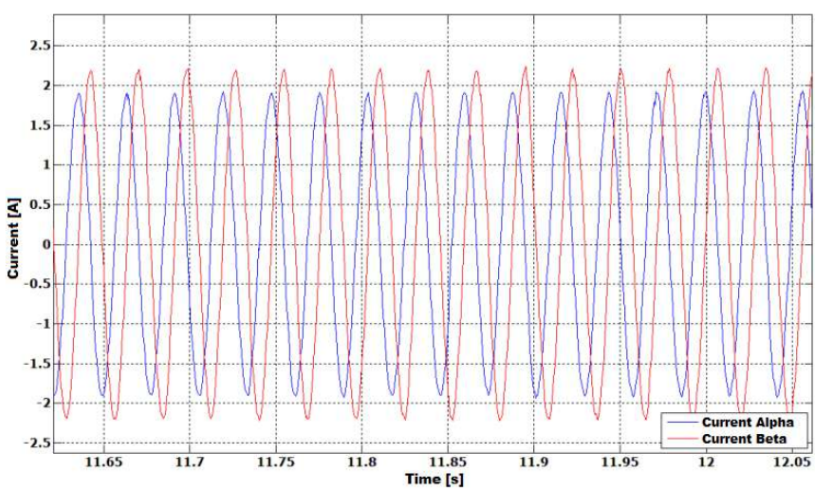

Fig. 11. Detail of the currents of $\alpha$ and $\beta$ axes at $800 \mathrm{rpm}$.

\section{B. Motor at 1800 rpm with a Constant Load of $1 \mathrm{Nm}$}

Figure 12 shows the speed response of the control. During the reversal, the same effect that occurs in the test at $800 \mathrm{rpm}$ with load is noticed.

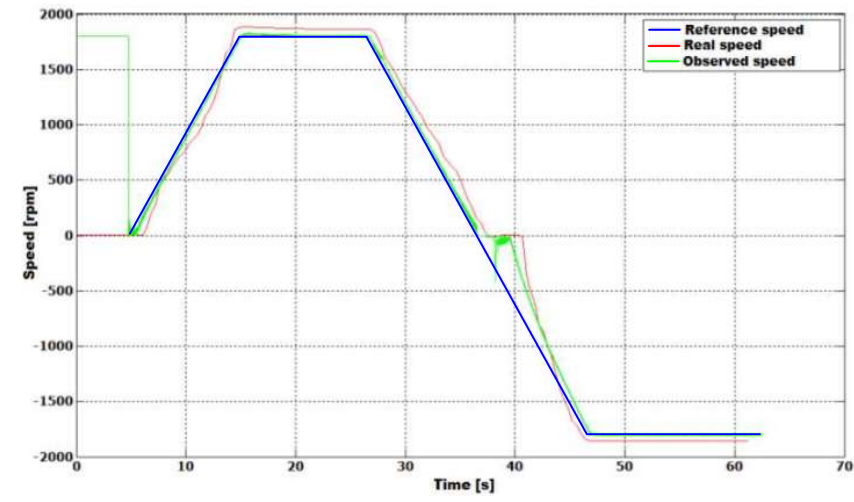

Fig. 12. Speed response at $1800 \mathrm{rpm}$.

There is a steady-state error around $60 \mathrm{rpm}$ relative to the actual speed, which represents a $3.33 \%$ error. In this way, it 
is noticed that with the increase of the speed of the machine, greater is the back-emf of the same, reducing the error of estimation of the speed.

Figure 13 shows the control of the $\mathrm{d}$ and $\mathrm{q}$ axis currents. Figure 14 shows the currents of the $\alpha$ and $\beta$ axes, which are the currents of the stationary reference frame. The steady-state $\alpha$-axis current has a peak value close to $1.8 \mathrm{~A}$, while for the $\beta$ axis this value is approximately $2.2 \mathrm{~A}$.

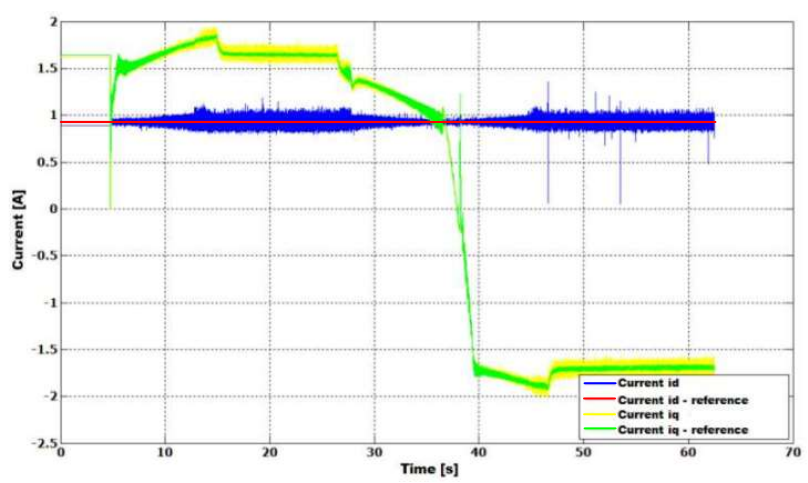

Fig. 13. Current control at $1800 \mathrm{rpm}$.

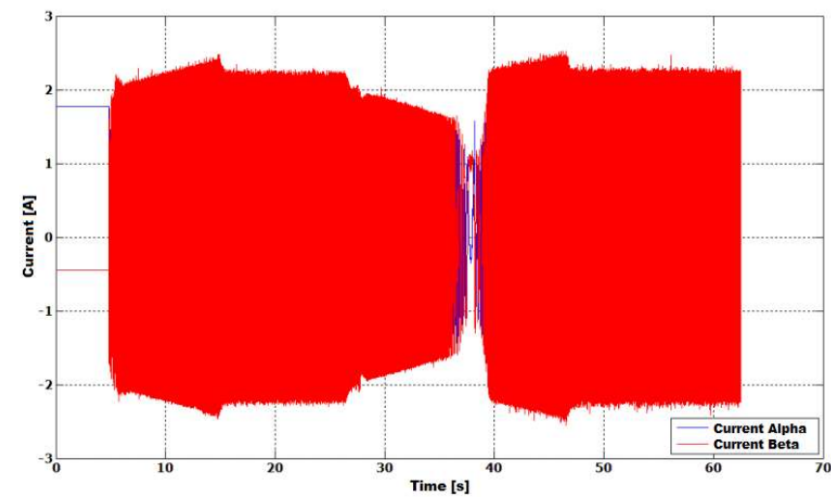

Fig. 14. $\alpha$ and $\beta$ axis currents at $1800 \mathrm{rpm}$.

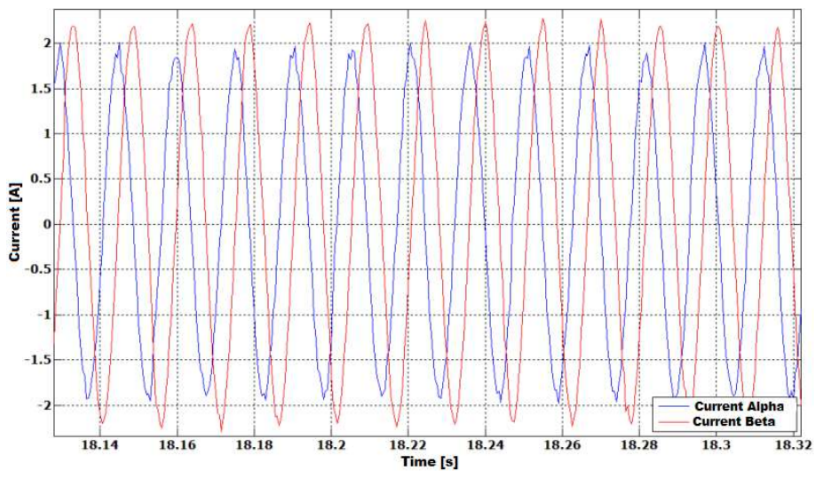

Fig. 15. Detail of the currents of $\alpha$ and $\beta$ axes at $1800 \mathrm{rpm}$.

To test the parameter sensitivity of the SMO, the rise of motor temperature was performed. The test consists to keep the motor running with constant torque (in this case $1.47 \mathrm{Nm}$ ) and a speed command of $1630 \mathrm{rpm}$, and while the temperature increases see how the real speed of the motor behaves. When the temperature increases, the stator and rotor resistance increases and mismatch the software values, causing errors on the speed estimation.

In Figure 16 the temperature of the stator is plotted, while in Figure 17, the speed error between the commanded speed $(1630 \mathrm{rpm})$ and the real speed of the motor are shown. These results show that the SMO is robust against parameters variation caused by temperature and the motor can still run without updating the stator resistance in the software with a temperature delta of almost $60^{\circ} \mathrm{C}$.

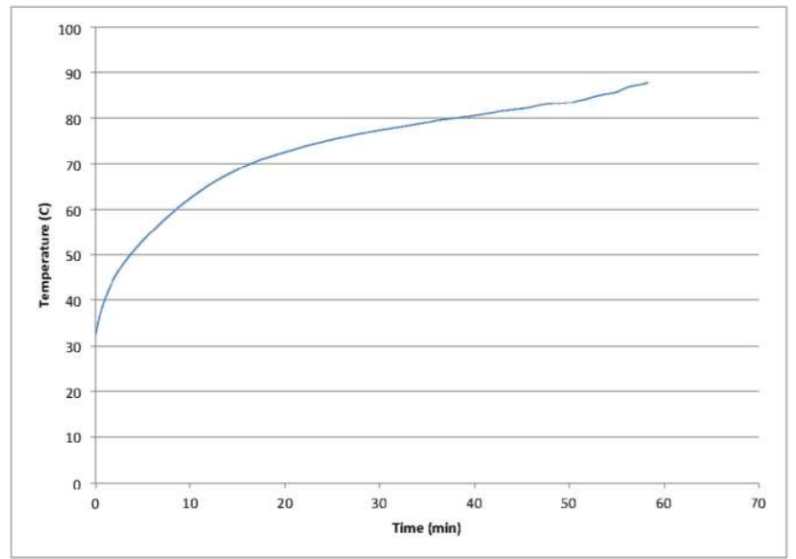

Fig. 16. Temperature rise curve of the motor.

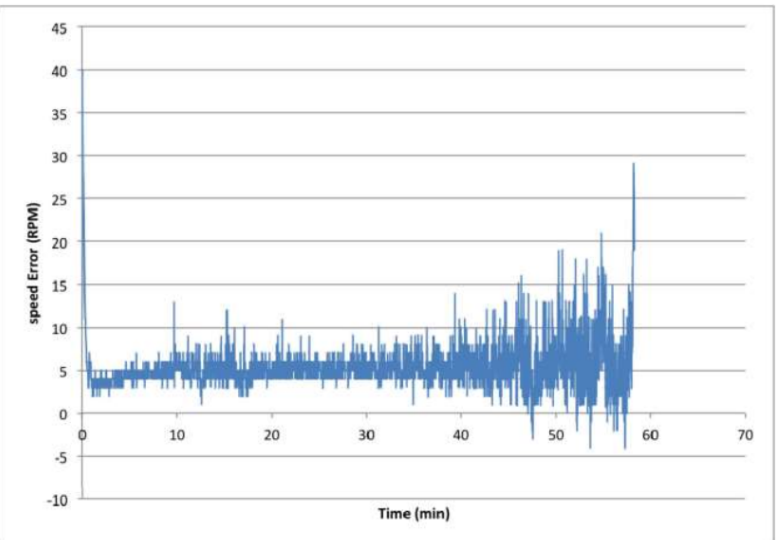

Fig. 17. Error between the commanded speed and the real speed of the motor.

\section{CONCLUSIONS}

The work presented showed the indirect vector control without the use of a speed sensor applied to an induction motor with a Scott-T connection in the stator. The velocity estimation was performed using an SMO. The results show that the speed estimation is good for slips values around the nominal, and some second order effects compensation are needed when working with higher slips or slow speeds.

Considering the industrial application, the motor and the control technique presented in this work have the objective to make possible an improvement in efficiency and provide an alternative to the industrial environment for the replacement of single phase motors in applications that want better efficiency and the ability to operate with variable speed, but always aiming at the lowest possible cost. 


\section{ACKNOWLEDGMENTS}

The authors wish to acknowledge the support provided by Santa Catarina State University Joinville and Whirlpool Corporation for this investigation.

\section{REFERENCES}

[1] H. B. Polli, F. Rosa, L. H. R. C. Stival, A. Nied, J. de Oliveira, "Sensorless Indirect Vector Control of na Induction Machine with a Scott-T Connection in the Stator", IEEE Industrial Electronics Society Montreal, QC, Canada, 2012.

[2] P. Huynh, H. Zhu, D. Aliprantis, "Parameter estimation for single-phase induction motors using test measurement data", 2016 North American Power Symposium (NAPS).

[3] P. Huynh, H. Zhu, D. Aliprantis, "Non-intrusive parameter estimation for single-phase induction motors using transient data", in Proc IEEE Power \& Energy Conf at Illinois, Urbana, IL.

[4] M. A. Hasan, S. K. Parida, "Modeling and analysis of single phase induction motor as a dynamic load in inverter dominated microgrid system", 7th International Conference on Power Systems (ICPS), 2017.

[5] Z. B. Duranay, H. Guldemir, "Selective harmonic eliminated V/f speed control of single-phase induction motor", IET Power Electronics, vol. 11, no. 3, pp. 477 - 483, March 2018.

[6] R. Rocha, L. S. M. Filho, J. C. D. de Melo, "A speed control for variable-speed single-phase induction motor drives", Int Symp Industrial Electronics, Dubrovnik, Croatia, 2005.

[7] N. A. E. R. Corporation, "A technical reference paper fault-induced delayed voltage recovery", NERC, Tech Rep, 2009.

[8] M. M. Elkholy, "Optimal energy saving for variable speed single phase induction motor drives", Nineteenth International Middle East Power Systems Conference (MEPCON), 2017.

[9] A. Nied, J. de Oliveira, L. H. R. C. Stival, H. B. Polli, "Improving Washing Machine Performance Using Single-Phase Induction Motor Field-Oriented Control", In: 39th Annual Conference on IEEE Industrial Electronics Society, Viena, 2013.

[10] D. W. Novotny, T. A. Lipo, Vector Control and Dynamics of AC Drives, Clarendon Press Oxford, 1998.

[11] M. B. R. Correa, C. B. Jacobina, A. M. N. Lima, E. R. C. da Silva, "Rotor-flux-oriented control of a single-phase induction motor drive", IEEE Transactions on Industrial Electronics, vol. 47, no. 4, pp. 832-841, August 2000.

[12] M. B. R. Correa, C. R. Jacobina, E. R. C. da Silva, A. M. N. Lima, "Field Oriented Control of a SinglePhase Induction Motor Drive", Conf Rec Power Electronics Specialists- PESC98, vol. 2, May 1998.
[13] J. Stepina, Single-Phase Induction Motors Construction, Theory and Calculation, 1st ed. ed., Magna Physics Publishing.

[14] P. C. da Silva, M. S. M. Cavalca., A. Nied, D. S. Matos, J. de Oliveira., "PI-MQR Adaptativo Aplicado a um Motor de Indução Trifásico Utilizando a DSPACE1103.”, in Induscon, Curitiba, Nov 2016.

[15] A. Derdiyok, M. K. Guven, H. Rehman, N. Inanc, L. $\mathrm{Xu}$, "Design and Implementation of a New Sliding-Mode Observer for Speed-Sensorless Control of Induction Machine", IEEE Trans On Industrial Electronics, vol. 49, no. 5, pp. 1177-1182, May 2002.

[16] J. Liu, J. Hu, L. Xu, "Sliding Mode Observer for Wide Speed Range Sensorless Induction Machine Drives: Considerations for Digital Implementation", IEEE International Conference on Electric Machines and Drives, San Antonio-USA, 2005.

\section{BIOGRAPHIES}

Paulo Cesar da Silva born in 10/01/1986 in Joinville-SC, is an Electrical Engineer (2013) and Master (2015) with Santa Catarina State University. He is currently an doctor student at Santa Catarina State University. His areas of interest are control of systems and electrical drives.

Horácio Beckert Polli born in 06/15/1985 in FlorianópolisSC, is a Master in Electrical Engineering (2012) with Santa Catarina State University. He is Senior Motor Calibration Engineer at General Motors Automobiles with 8 years of experience in sensorless/sensored Motor Control Solutions and powertrains, embedded software development and debugging, motor and hardware design support through modeling, simulation and experimental results.

Daniel dos Santos Matos born in 05/14/1983 in CuritibanosSC, is an Electrical Engineer (2014) and Master (2016) with Santa Catarina State University. He is currently an professor with the Department of Electrical Engineering, Federal Institute of Paraná and is an doctor student at Santa Catarina State University. His areas of interest are control of systems, power electronics and electrical drives.

José de Oliveira born in 06/15/1961 in Mandaguari-PR, is an Electrical Engineer (1986), Master (1994) and Doctor in Electrical Engineering (2000) with the Federal University of Santa Catarina. He is currently a full professor with the Department of Electrical Engineering, Santa Catarina State University. His areas of interest are control systems, electrical machine actuation and power electronics.

Ademir Nied born in 06/12/1962 in Santo Ângelo-RS, is an Electrical Engineer (1987), Master (1995) and Doctor in Electrical Engineering (2007) with Federal University of Minas Gerais. He is currently an associate professor with the Department of Electrical Engineering, Santa Catarina State University. His areas of interest are electrical machines, control of electrical drives and neural networks. 